\title{
A Clinical Analysis on Schwannoma in Head and Neck
}

\author{
Sang Ho Lim, Kyung Suk Lee, Byung Un Hwang, Hee Tak Park, Yun Su Yang and Ki Hwan Hong \\ Department of Otolaryngology-Head and Neck Surgery, College of Medicine, Chonbuk National University, Jeonju, Korea
}

\author{
두경부에 발생한 신경초종에 대한 임상적 고찰 \\ 임상호 · 이경석 · 황병언 · 박희택 · 양윤수 · 홍기환 \\ 전북대학교 의학전문대학원 이비인후-두경부외과학교실
}

\author{
Received January 18, 2011 \\ Revised March 15, 2011 \\ Accepted March 17, 2011 \\ Address for correspondence \\ Ki Hwan Hong, MD \\ Department of Otolaryngology-Head \\ and Neck Surgery, College of \\ Medicine, Chonbuk National \\ University, 634-18 Geumam-dong, \\ Deokjin-gu, Jeonju 561-712, Korea \\ Tel $+82-63-250-1980$ \\ Fax $+82-63-250-1986$ \\ E-mail khhong@chonbuk.ac.kr
}

Background and Objectives Neurogenic tumors in the head and neck are relatively rare and constitute around $0.5 \%$ of all head and neck tumors. Schwannoma, among neurogenic tumors, is a benign tumor originating from the spinal nerve root, peripheral nerve and all kinds of cranial nerves except the optic nerve and olfactory nerve. By presenting a series of head and neck schwannomas treated during a fifteen-year period, we aimed to analyze the clinical features, diagnosis, treatment and prognosis of schwannomas retrospectively.

Subjects and Method We retrospectively reviewed and analyzed clinical records of 34 patients with head and neck schwannomas who were treated surgically at the University Hospital from January, 1995 to January, 2010.

Results We found 34 cases of schwannoma in the head and neck. Among the patients, 14 were males and 20 were females. The most common age group was the 60 's while the most common site was the parapharyngeal space. The most common presenting symptom was palpable neck mass and the mean duration of symptoms was 41.6 months. The most common nerve of origin was the cervical plexus (29.4\%). Preoperative diagnostic tools were FNA, CT and MRI. All cases were treated surgically and the most common postoperative complication was both transient and permanent voice changes. The mean follow-up period was 18.3 months and recurrence was not found during this period.

Conclusion Thirty-four cases of schwannoma in the head and neck were presented with respect to their clinical features.

Korean J Otorhinolaryngol-Head Neck Surg 2011;54:278-82

Key Words Schwannoma in head and neck - Clinical analysis.

\section{서 론}

신경초종은 시신경과 후각신경을 제외한 모든 뇌신경, 척 추신경 및 말초신경 등 신경초로 덮여있는 어떤 신경에서든 발생할 수 있는 양성종양으로서 Verocay ${ }^{1)}$ 가 1910년 신경종 (neuroma)으로 명명한 이래 여러 가지 이름으로 불려져 왔 다. 최근 주로 사용되는 Schwannoma와 neurilemmoma 는 거의 혼동하여 같은 의미로 사용되고 있으나 미세구조, 조직학적 관찰에서 Schwann 세포는 단지 신경초의 내층을 구성하고 있으며 외층은 특별한 명명이 없다. 그러므로 neu- rilemmoma라는 말은 신경초의 양 층으로부터 기원한 종 양을 나타낼 때 사용된다. ${ }^{2}$ 전체 신경초종의 약 25 40\%가 두경부의 신경조직에서 발생하며, 대부분이 전정신경에서 기원한다. 그 외에 혀, 인두, 입술, 연구개 등에서 드물게 나 타남을 보고하고 있다. ${ }^{3,4}$ 경부에서는 미주신경과 교감신경, 상완신경총 등에서 기원하는 것으로 보고하고 있다. 대부분 증상이 없기 때문에 조기진단이 어렵고 대개 30,40 대에 흔 하게 발생하며 악성 신경초종은 매우 드문 것으로 알려져 있다. ${ }^{5)}$ 치료는 신경기능을 보존하면서 외과적으로 절제하는 것이다.6) 국내에서는 경부 및 안면부에 발생한 신경초종에 
대한 증례보고는 있었으나 두부를 포함하여 여러 환자들을 대상으로 임상분석을 실시한 보고는 드물다. 이에 본 저자 들은 조직학적으로 확진된 두경부에 발생한 신경초종의 임 상양상 및 진단, 치료에 대해 분석하고자 하였다.

\section{대상 및 방법}

1995년 1월부터 2010년 1월까지 본원 이비인후과에서 수 술 후 조직학적으로 확진된 두경부에 발생한 신경초종 환자 34 명을 대상으로 후향적으로 조사하였다. 대상 환자군은 두개강내에 발생하거나 측두골 부위에 발생한 신경초종 환 자는 제외하여 설정하였고, 전체 34명 중 여성이 20명(58.8\%), 남성이 14 명(41.2\%)이었다. 연령분포는 6 세부터 76 세까지로 평균 나이는 49.2세였다(Fig. 1). 환자군의 임상증상 및 지 속기간, 종물의 위치와 크기, 기원한 신경, 진단, 치료, 술 후 합병증, 동반 질환 및 예후에 대해 후향적으로 분석하였으 며 평균 추적관찰 기간은 18.3 개월(1개월 8.3년)이었다.

\section{결 과}

\section{임상 증상(Table 1) 및 지속기간}

주 증상은 경부 종물이 23예(67.6\%)로 가장 많았고 그 외 에 연하곤란을 호소한 경우가 3 예(8.8\%)였으며, 구인두 불편

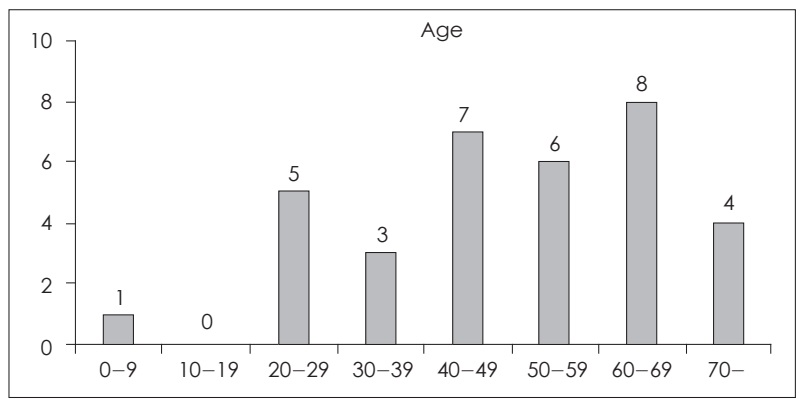

Fig. 1. Age distributions.

Table 1. Clinical symptoms

\begin{tabular}{lc}
\hline & Number of patient \\
\hline Palpable neck mass & 23 \\
Swallowing difficulty & 3 \\
Oropharyngeal discomfort & 2 \\
Headache & 1 \\
Mass in EAC & 1 \\
Nasal mass & 1 \\
Otalgia & 1 \\
Voice change & 1 \\
Mild dyspnea & 1 \\
\hline
\end{tabular}

EAC: external auditory canal
감 2예(5.9\%), 목소리 변화, 경부 종물을 동반한 두통, 외이 도 종물, 이개부 통증, 비강내 종물 및 경한 호흡 곤란을 호 소한 경우가 각각 1 예(2.9\%)씩 조사되었다. 증상의 지속기 간은 평균 41.6 개월(1개월 20년)이었다.

종물의 위치(Table 2)와 크기(Fig. 2)

모든 예에서 양측성인 경우는 없었고, 일 측(우측)에 다발 성으로 발생한 경우가 1예(2.9\%), 우측인 경우가 16예(47.1\%), 좌측은 18예(52,9\%)였다. 경부 level에 따라 분류해보면, level II에 14예(41.2\%)로 가장 많았고, 다음으로 level I 7 예(20.6\%), level III, IV, VI 각 3예(8.8\%), level V, 외이도 내, 비강내, 저작 공간에 각 1예(2.9\%)순이었다. 공간별로 보 면 부인두 공간에 20예가 발생하여 가장 흔하게 발생하는 것 으로 확인되었고, 내장 공간이 5 예, 악하강, 후경부 공간, 이 하선 공간에서 각 2 예, 저작 공간 및 외이도, 비강내에서 각 1 예가 관찰되었다. 종물의 크기는 지름이 평균 $3.7 \mathrm{~cm}(0.6$

Table 2. Site distribution of mass

\begin{tabular}{lc}
\hline & Number of patient \\
\hline Level I & 7 \\
Level II & 14 \\
Level III & 3 \\
Level IV & 3 \\
Level V & 1 \\
Level VI & 3 \\
\hline & Number of patient \\
\hline Parapharyngeal space & 20 \\
Visceral space & 5 \\
Parotid space & 2 \\
Posterior cervical space & 2 \\
Submadibular space & 2 \\
Masticator space & 1 \\
External auditory canal & 1 \\
Nasal cavity & 1 \\
\hline
\end{tabular}

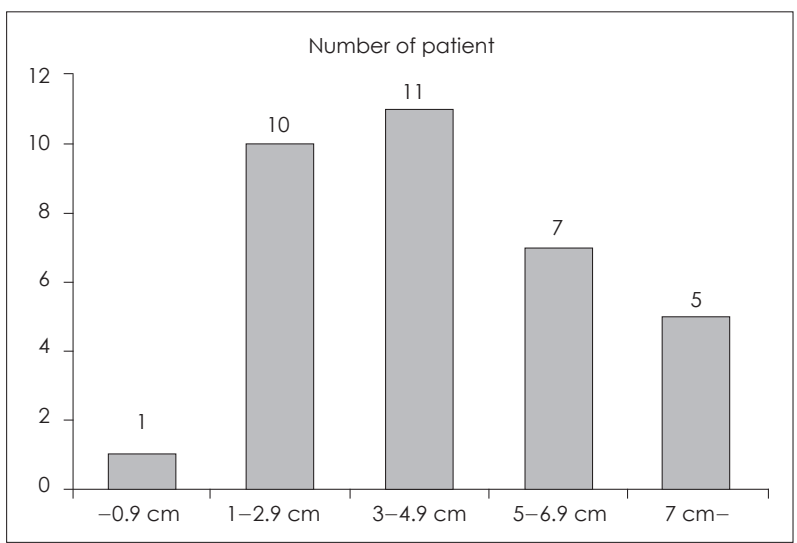

Fig. 2. Size distributions of mass. 
$10 \mathrm{~cm}$ )이었다.

기원한 신경(Table 3)

기원한 신경은 수술시 시야를 통한 직접적인 확인과 수술 전 환자의 증상이나 술 후 발생한 증상으로 추측하여 확인 하였으며 이에 따라, 경부 교감신경이 10예(29.4\%)로 가장 많 았으며, 미주신경이 7예(20.6\%)로 그 다음 순서를, 상완 신경 총, 안면신경, 되돌이 후두신경이 각 3 예(8.8\%), 설하신경이 2 예(5.9\%)씩 있었으며 기원한 신경을 확인할 수 없었던 경우 도 6예(17.6\%) 있었다.

\section{진 단}

진단은 34 명 중 총 23 예에서 세침흡인세포검사를 시행하 였으나 신경초종으로 진단된 경우는 6예(26.1\%)였으며 나머 지 17예에서는 부족한 세포수로 인해 진단이 불가능하거나, 침샘에서 기원한 다형 선종, 또는 비특이적 임파선을 의심하 였다. 모든 예에서 컴퓨터단층촬영(Fig. 3)을 시행하였으며 3 예에서는 자기공명영상검사를 또 다른 3 예에서는 초음파 검사를 같이 시행하였다. 컴퓨터단층촬영 및 자기공명영상 검사상에서 신경원성 종양으로 의심된 경우는 26예(76.5\%) 였다. 초음파를 같이 시행한 경우는 모두 95년에서 99년 사 이에 진단이 이루어진 환자였으며, 자기공명영상검사의 경우 환자에게 선택하게 하여 시행하였다.

Table 3. Origin of nerve

\begin{tabular}{lc}
\hline & Number of patient \\
\hline Cervical plexus & 10 \\
Vagus nerve & 7 \\
Brachial plexus & 3 \\
Facial nerve & 3 \\
Recurrent laryngeal nerve & 3 \\
Hypoglossal nerve & 2 \\
Unknown origin & 6 \\
\hline
\end{tabular}

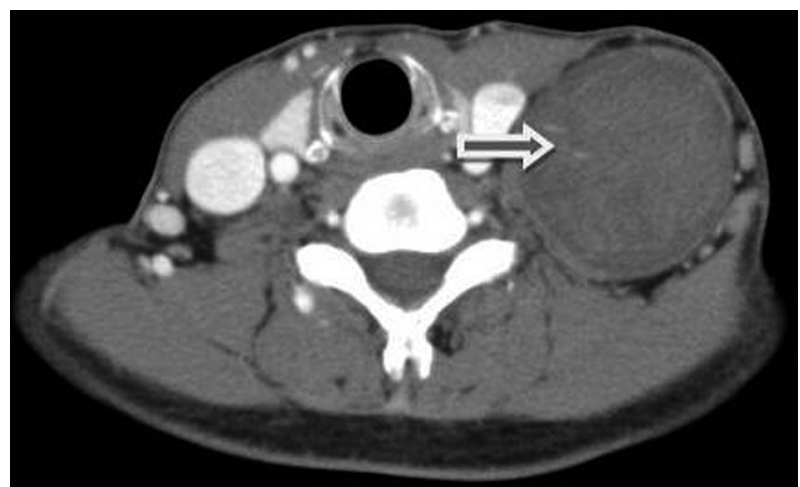

Fig. 3. Neck CT finding. Huge sized, well defined round solid mass with inhomgeneous enhancement in Lt lateral neck (arrow).
치 료

34 명 중 29명의 환자에서 경부접근법을 통해 수술을 시 행하였으며, 종물이 안면신경에서 발생하여 이하선 내에 있 었던 1예에서는 이하선 천엽절제술을 통해 제거하였고 종물 이 외이도벽을 일부 파괴하며 외이도내를 가득 채우고 있었 던 1예에서는 외이도를 통한 접근법을 사용하였다. 또한 2 예에서는 구강내 접근법을 이용하여 제거하고 경과 관찰하 였으나 관찰 기간 중 재발 소견은 보이지 않았고, 1 예에서는 비강내 종괴로 내시경적 접근법을 통해 수술 후 경과 관찰 하였다. 총 34 예 중 28 예에서 기원한 신경을 추정할 수 있었 으며 이 중 28 예에서는 신경을 보존하면서 수술하였고, 나머 지 6예에서는 종괴에 인접한 신경구간의 일부를 같이 절제 하여 신경을 완전히 보존하기가 어려웠다. 신경의 일부를 같 이 절제한 경우는 모두 종물이 신경에 단단히 유착되어 있어 박리가 불가능한 경우였으며 후유증이 지속적으로 관찰되 었다. 대부분 완전 절제를 선택하였으며, 절제된 종물은 모 든 예에서 핵 형 울타리모양을 가진 치밀한 Schwann세포 를 특징으로 하는 Antoni A와 느슨하게 배열된 세망조직에 서 세포의 다형태성이 표현된 Antoni B의 혼합형을 보이며 방추형의 세포들이 밀도 높게 모여 있으면서 일부 세포들이 나란히 배열되는 등 병리조직학적으로 신경초종에 합당한 소견을 보였다. 뿐만 아니라 검체 조직은 S-100에 양성 소견 을 보였으나 GFAP, smooth muscle actin, desmin 등에 는 음성소견을 보여 신경초종으로 진단할 수 있었으며 악성 화소견도 보이지 않았다(Fig. 4).

\section{술 후 합병증(Table 4)}

수술 시 신경을 보존한 28예의 경우 모두 일시적인 합병 증만 관찰되었다. 교감신경에서 발생한 10예 중 3예에서 Horner 증후군이 발생하였으나 모두 추적 관찰기간 중 증 상이 회복되었으며, 상완신경총에서 발생한 3 예 중 2예에서 는 동측 손의 감각 저하가 나타났으나 곧 회복되었다. 미주 신경과 되돌이 후두신경에서 발생한 각 1 예의 환자의 경우 동측 성대의 일시적인 운동 감소가 관찰되었고, 이는 3 개월 이내에 회복되었다. 이에 반해 신경의 일부를 함께 절제한 6 예에서는 모두 영구적인 합병증이 발생하였는데 이 중 설하 신경에서 발생한 1 예와 안면신경에서 기원한 1 예는 신경의 손상이 심하여 재건술을 시행하였으나 회복되지 않았고, 설 하신경에서 발생한 2예는 혀의 운동 장애가 관찰되었으며, 안면신경에서 기원한 1 예에서는 침범된 신경의 지배영역에 마비증상이 관찰되었다. 미주신경에서 발생한 7예 중 1예에 서 신경의 손상이 있었고 술 후 성대 마비가 발생하였으며 되돌이 후두 신경에서 기원한 3예 중 2예에서도 술 후 성대 

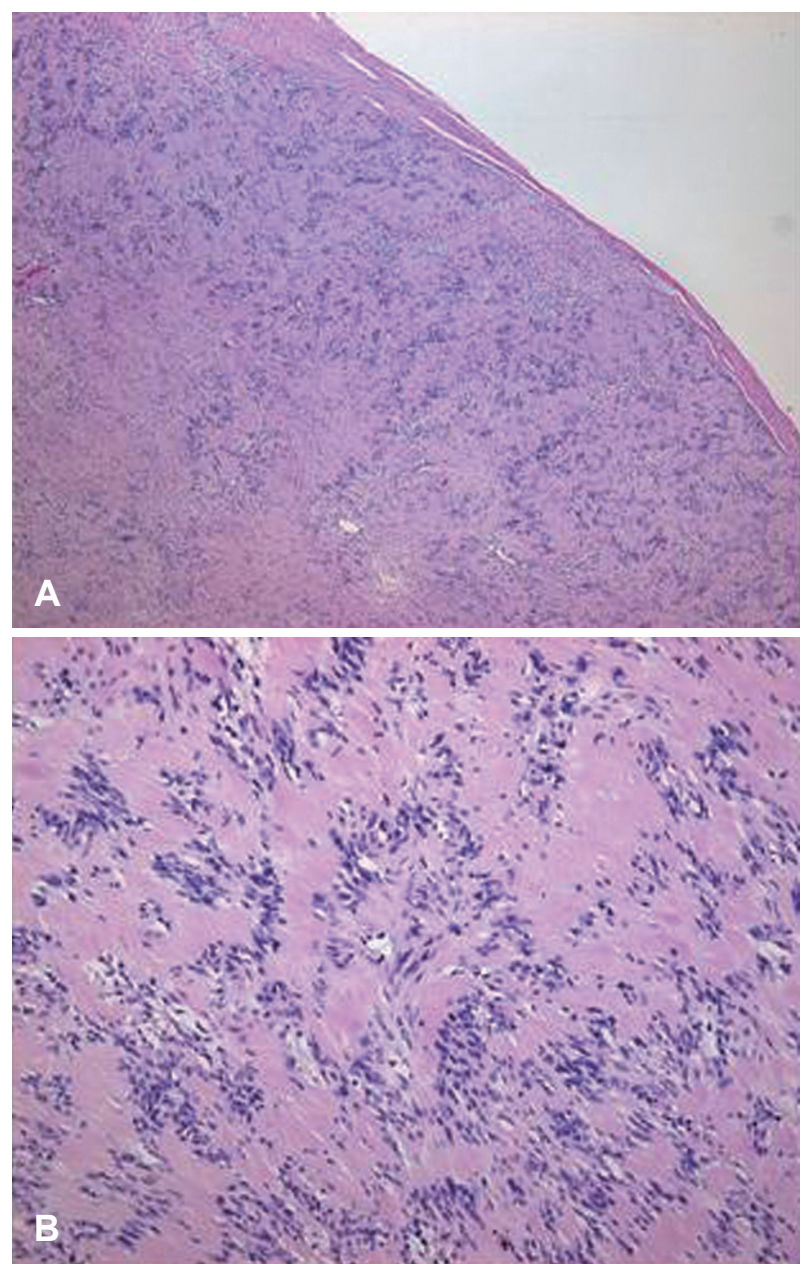

Fig. 4. Histologic finding. The tumor was surrounded by discrete, confining capsule (H\&E, $x 40)(A)$. A classic histologic finding of nerilemmoma is shown, that is cellular Antoni $A$ areas with nuclear palisading and less cellular Antoni B areas (H\&E, x200)(B).

마비가 관찰 되었다. 이후 1 예서 제1형 갑상성형술을 시행하 였고, 나머지 2예는 경과 관찰하였다. 기원한 신경을 확인하 지 못한 6 예에서는 모두 합병증이 관찰되지 않았다. 신경과 관련하지 않은 합병증으로는 술 후 혈종이 1예 관찰되었고, 혈종을 제거하기 위한 재수술이 필요하였다.

\section{동반 질환}

34예의 환자 중 진단 전 후에 동반된 질환이 있었던 환자 는 5 예였고, 이 중 2 예는 이하선 및 설하선의 암종으로 진단 되어 추가적인 수술 및 항암 치료가 시행 되었다. 다른 1예에 서는 비구순낭이 관찰되어 수술시 같이 제거하였다.

\section{고 찰}

신경초종은 말초신경에서 발생하는 가장 흔한 종양이지만 상대적으로 드문 질환이다. ${ }^{7)}$ 신경초종은 뇌신경, 교감신경,
Table 4. Postoperative complication

\begin{tabular}{lcc}
\hline & $\begin{array}{c}\text { Number } \\
\text { of patient }\end{array}$ & Feature \\
\hline Horner's syndrome & 3 & Temporary \\
Numbness of Ipsilateral arm & 2 & Temporary \\
Voice change & 2 & Temporary \\
Voice change & 3 & Permanent \\
Limitation of tongue movement & 2 & Permanent \\
Facial palsy & 1 & Permanent \\
Postoperative hematoma & 1 & Temporary \\
\hline
\end{tabular}

말초신경에서 모두 생길 수 있으나 두경부 영역에서 가장 흔 하게 발생하며 전정신경에서 가장 흔하게 관찰된다. 경부에 서는 대개 미주신경이나 교감신경에서 발생하며 흔히 경부 종물이 주증상으로 나타난다. ${ }^{8)}$ 이번 연구에서는 경부 교감 신경이 가장 흔하게 발견되었으며 그 외 미주신경, 기원 미상, 상완 신경총, 안면신경순이었다. 신경초종은 어떤 나이에서 도 생길 수 있으나 30,40 대에서 흔한 것으로 알려져 있고 성 비에도 차이가 없는 것으로 알려져 있으며 대개 천천히 자라 고 특별한 증상도 없는 경우가 많은 것으로 알려져 있으나.,10) 이번 조사에서는 60 대에서 호발하였으며, 여자에게서 좀 더 많이 발생하는 것으로 평가 되었다.

신경초종은 신경섬유를 직접 침범하지는 않으며 정상 신경 섬유와 분명한 경계를 가지고 있어 신경전도 검사상 이상소 견이 나타나는 경우는 적다. ${ }^{7)}$ 하지만 종물이 자라서 커지는 경우 주위 조직에 압박괴사를 일으킬 수 있어 위험해지는 경 우가 있다. ${ }^{11)}$ 간혹 애성이나 연하곤란, 어깨움직임 저하 등의 증상이 나타나기도 한다. 컴퓨터단층촬영상 신경초종은 근 육과 비교했을 때 비슷한 저밀도 음영 양상으로 보이며, 조 영제 증강 후에는 주변부의 고밀도 음영을 보인다. 자기공명 영상검사도 진단에 매우 도움을 준다. T1WI에서는 저신호강 도 소견을 보이고, 조영 증강된 T1WI에서는 고신호강도로 나타나며, T2WI에서도 고신호강도의 종물로 보인다. ${ }^{2,12,13)}$ 세침흡인세포검사는 유용한 정보를 주지만 정확하지 않으 며 대부분의 경우에 있어서는 절제 생검이 필요하다. $\mathrm{Yu}$ 등 의 발표에 따르면 9 개의 세침흡인세포검사에서 1 예에서만 신경초종이 진단되었다. $\mathrm{Yu}$ 등 ${ }^{14}$ 은 신경초종의 세침흡인세 포검사에서 세포수가 적거나 진단에 부적합하게 나오는 이 유로 낭변성이나 조밀한 버팀질 성분이 많기 때문이며 세포 성분이 나온다고 해도 진단에는 문제가 있을 수 있다고 하였 다. 하지만 이러한 결과에도 불구하고 비용-효과를 고려해 볼 때 세침흡인세포검사는 필요하다고 보고하였다. 조직학적 으로 신경초종은 두 가지 형태로 구분되는데 Antoni type $\mathrm{A}$ 와 B가 있다. Antoni type A는 핵형 울타리모양을 가진 치밀한 Schwann세포가 특징적이며, Antoni type B는 느 
슨하게 배열된 세망 조직에서 세포의 다 형태성이 표현된다 (Fig. 4). 이들 두 가지 형태는 대부분의 신경초종에서 항상 발견되고, 국소재발이나 악성화의 빈도와는 관계가 없는 것 으로 알려져 있다. ${ }^{2)}$ 신경초종은 방사선치료에 저항성이 있 으므로, 추천되는 치료는 외과적 절제술이다..$^{2,6,15)}$ 수술은 주로 측 경부 접근법에 의해 이루어진다. 과거에는 종양재 발 방지를 위하여 모신경섬유를 포함한 종양 전 절제술을 시행하였으나 최근에는 신경기능 보존을 위하여 피막 내 종 양절제술을 시행한다. 이들 종양의 대부분은 피막화되어 있 고 신경의 섬유가 종양의 표면을 둘러싸면서 주행하는 경우 가 대부분이지만 어떤 경우에는 신경섬유의 주행이 모호하 여 박리가 어렵다. 만약 신경 주분지를 보존하기 어렵고, 침 범부위가 $2 \mathrm{~cm}$ 이내라면 병소를 절제하고, 잘린 부위를 미 세현미경하 재접합술을 시행할 수 있다. 병소가 $2 \mathrm{~cm}$ 이상 일 때는 대이개신경을 이용하여 삽입이식의 방법을 고려할 수도 있다. ${ }^{2)}$ 이번 34 예의 환자 중 잘린 신경을 재접합한 경 우는 1 예, 대이개신경을 이용하여 재건한 경우도 1 예 있었으 나 모두 결과가 좋지는 않았고, 미주신경의 절단으로 인해 성대마비가 생긴 경우는 제1형 갑상성형술을 시행하여 목소 리의 변화를 교정하였다. 신경초종의 재발은 낮은 것으로 알려져 있으며,16) 전이를 하지 않고 ${ }^{17)}$ 신경섬유종과는 달리 거의 항상 양성이기 때문에 가능한 한 보존적 치료를 시행 하는 것이 좋다. ${ }^{18)}$

그러나 간혹 양성 신경초종이 악성화되는 보고도 있기 때 문에 술 후 지속적인 추적 관찰이 필요하다. ${ }^{19)}$ 술 후 합병증 으로는 성대마비, 인후두마비, Horner 증후군, 연하장애, 어 깨 움직임 저하, 일시적인 빈맥 등이 보고되었다. ${ }^{8)}$ 이번 결과 에서는 13 예에서 합병증이 발생하였고, 성대마비 5예(38.5\%), Horner's syndrome 3예(23.1\%), 상완의 운동능력 저하 2 예(15.4\%), 안면신경마비 1예(7.7\%), 혀의 운동성저하 2 예 (15.4\%)가 관찰되었다.

저자들은 본원 이비인후과에서 수술을 받은 34예의 두경 부 신경초종 환자를 후향적으로 분석하여 다음과 같은 결 론을 얻었다. 이 기간 동안 두경부에 발생한 신경초종은 60 대에 가장 호발하였으며 여자에게서 발생 빈도가 높은 것으 로 나타났다. 가장 흔한 증상은 무통성의 경부 종물이었으 며 종물의 위치는 level II에서 그리고 부인두 공간에서 가 장 흔하게 발견되었고 좌측과 우측에 큰 차이는 없었다. 기 원한 신경은 경부 교감신경이 가장 흔하였고(23.8\%), 미주 신경, 기원 미상순이었으며, 이러한 신경의 주행 위치에 따라 경부 level II와 부인두 공간이 종양 발생의 가장 흔한 위치
로 생각되었다. 진단은 세침흡인세포 검사의 경우 $16.7 \%$ 의 민감도를 나타내었고 컴퓨터단층촬영 및 자기 공명영상검사 에서는 $76.2 \%$ 의 민감도를 나타내었다. 수술은 경부접근법 만 사용한 경우가 가장 많았으며 술 후 합병증으로는 성대 마비가 가장 흔하였다. 신경을 보존한 예에서는 모두 영구적 인 합병증 소견은 관찰되지 않았으며 전 예에서 추적 기간 중 재발소견은 관찰되지 않았다. 신경초종의 수술에 있어서는 가능한 한 보존적인 수술을 하는 것이 추천된다.

\section{REFERENCES}

1) Kim MS, Kim YH, Hong WP. A case of neurilemmoma of the posterior wall of the hypopharynx. Korean J Otolaryngol-Head Neck Surg 1998;41(2):274-7.

2) Park SY, Min JH, Park SJ, Ryu JW. Two cases of neurilemmoma of the cervical vagus nerve including intracapsular enulceation of nerve preservation. Korean J Otolaryngol-Head Neck Surg 2001; 44(12):1350-4.

3) Saydam L, Kizilay A, Kalcioglu T, Gurer I. Ancient cervical vagal neurilemmoma: a case report. Am J Otolaryngol 2000;21(1):61-4.

4) Chang SC, Schi YM. Neurilemmoma of the Vagus nerve. A Case Reportand Brief Literature Review. Laryngoscope 1984;94(7):946-9.

5) Carinci F, Carls FP, Grasso DL, Pelucchi S, Pastore A. Schwannoma of the parapharyngeal space. J Craniofac Surg 2000;11(4):367-70.

6) Leu YS, Chang KC. Extracranial head and neck schwannomas: a review of 8 years experience. Acta Otolaryngol 2002;122(4):435-7.

7) Lee SH, Jung HG, Park YC, Kim HS. Results of neurilemoma treatment: a review of 78 cases. Orthopedics 2001;24(10):977-80.

8) Gore DO, Rankow R, Hanford JM. Parapharyngeal neurilemmoma. Surg Gynecol Obstet 1956;103(2):193-201.

9) Thaler SU, Smith HW. Neurilemmoma of the pharynx. Arch Otolaryngol 1966;83(3):233-6.

10) Apte BP, Tepan MG. Neurilemmoma of the pharynx. J Laryngol Otol 1969;83(4):387-91.

11) Pantazopoulos PE. Schwanomas of nose, oral cavity and pharynx. Acta Otolaryngol 1965;60:97-104.

12) Weber AL, Montandon $C$, Robson CD. Neurogenic tumors of the neck. Radiol Clin North Am 2000;38(5):1077-90.

13) Asaoka K, Sawamura Y, Murai H, Satoh M. Schwannoma of the oculomotor nerve: a case report with consideration of the surgical treatment. Neurosurgery 1999;45(3):630-3; discussion 633-4.

14) $\mathrm{Yu}$ GH, Sack MJ, Baloch Z, Gupta PK. Difficulties in the fine needle aspiration (FNA) diagnosis of schwannoma. Cytopathology 1999; 10(3):186-94.

15) Kim MS, Kim YH, Jung HJ, Hong WP. A case of neurilemmoma of the posterior wall of the hypopharynx. Korean J Otolaryngol-Head Neck Surg 1998;41(2):274-7.

16) Fournier J, St Pierre S, Morrissette Y. Neurilemmoma of the parapharyngeal space. Report of three cases and review of the literature. J Otolaryngol 1979;8(5):439-42.

17) Iliades CE, Hock H, Gelman H. Neurilemmoma of the pharynx. Laryngoscope 1972;82(3):430-7.

18) Marshall JF, Bradford GE. Neurilemmoma of the pharnyx. South Med J 1956;49(4):347-8.

19) al-Otieschan AA, Saleem M, Manohar MB, Larson S, Atallah A. Malignant schwannoma of the parapharyngeal space. J Laryngol Otol 1998;112(9):883-7. 